\title{
A pragmatic approach to infants with Robin sequence: a retrospective cohort study and presence of a treatment algorithm
}

\author{
Emma C. Paes • Daan P. F. van Nunen • Lucienne Speleman • \\ Marvick S. M. Muradin • Bram Smarius • Moshe Kon • \\ Aebele B. Mink van der Molen • Titia L. E. M. Niers • \\ Esther S. Veldhoen • Corstiaan C. Breugem
}

Received: 30 September 2014 / Accepted: 14 January 2015 / Published online: 15 February 2015

(C) The Author(s) 2015. This article is published with open access at Springerlink.com

\begin{abstract}
Objectives Initial approaches to and treatments of infants with Robin sequence (RS) is diverse and inconsistent. The care of these sometimes critically ill infants involves many different medical specialties, which can make the decision process complex and difficult. To optimize the care of infants with RS, we present our institution's approach and a review of the current literature

Material and methods A retrospective cohort study was conducted among 75 infants diagnosed with RS and managed at our institution in the 1996-2012 period. Additionally, the conducted treatment regimen in this paper was discussed with recent literature describing the approach of infants with RS. Results Forty-four infants (59 \%) were found to have been treated conservatively. A significant larger proportion of
\end{abstract}

E. C. Paes • D. P. F. van Nunen • B. Smarius • M. Kon •

A. B. M. van der Molen • C. C. Breugem

Department of Plastic, Reconstructive and Hand Surgery,

Wilhelmina Children's Hospital, Utrecht, The Netherlands

L. Speleman

Department of Otorhinolaryngology, Wilhelmina Children's

Hospital, Utrecht, The Netherlands

\section{S. M. Muradin}

Department of Oral and Cranio-Maxillofacial Surgery, Wilhelmina

Children's Hospital, Utrecht, The Netherlands

T. L. E. M. Niers $\cdot$ E. S. Veldhoen

Department of Pediatrics, Wilhelmina Children's Hospital,

Utrecht, The Netherlands

E. C. Paes $(\bowtie)$

Department of Pediatric Plastic Surgery, Wilhelmina Children's Hospital Utrecht, PO Box 85500, 3508 GA Utrecht, The Netherlands

e-mail: emmapaes@gmail.com nonisolated RS infants than isolated RS infants needed surgical intervention ( 53 vs. $25 \%, p=.014$ ). A mandibular distraction was conducted in $24 \%(n=18)$ of cases, a tracheotomy in $9 \%(n=7)$, and a tongue-lip adhesion in $8 \%(n=6)$. Seventyseven percent of all infants had received temporary nasogastric tube feeding. The literature review of 31 studies showed that initial examinations and the indications to perform a surgical intervention varied and were often not clearly described. Conclusions RS is a heterogenic group with a wide spectrum of associated anomalies. As a result, the decisional process is challenging, and a multidisciplinary approach to treatment is desirable. Current treatment options in literature vary, and a more uniform approach is recommended.

Clinical Relevance We provide a comprehensive and pragmatic approach to the analysis and treatment of infants with $\mathrm{RS}$, which could serve as useful guidance in other clinics.

Keywords Pierre Robin · Mandibular distraction .

Tracheotomy · Tongue-lip adhesion · Approach · Treatment . Multidisciplinary team

\section{Introduction}

Mandibular micrognathia, glossoptosis with subsequent airway obstruction, is the original triad of symptoms described by Pierre Robin in 1923 [1]. By 1934, the frequent association of a cleft palate was noted by him [2]. These features combined are currently known as Robin sequence (RS). RS may be an isolated condition, but an associated syndrome is present in about $45-80 \%$ of cases [3]. Reported incidences are 
estimated to be 1:8000 to 1: 14000 births [4-6]. Symptoms of the condition include varying degrees of upper airway obstruction (UAO) and feeding problems, leading to failure to thrive $[7,8]$. Mortality rates vary from 0 to $26 \%$ and are most usually caused by severe UAO leading to obstructive apnea and secondary cardiac problems [8].

Infants born with RS have been treated with numerous different methods [9]. Most airway management strategies initiate treatment with positional change [7]. With an inadequate response, nonsurgical interventions, such as the use of a nasopharyngeal airway $[10,11]$ or a palatal plate [12-15], are commonly pursued. Still, in some cases, there can be more severe respiratory obstruction or failure to thrive, necessitating some other form of intervention [16]. This decision-making process can be challenging for caregivers. To date, many authors have described their preferred surgical techniques, such as tongue-lip adhesion (TLA) [17, 18], tracheotomy [19, 20], subperiosteal release of the floor of the mouth [21, 22], or mandibular distraction osteogenesis (MDO) [23, 24].

Currently, guidelines are lacking, and there is a paucity and discrepancy of information in the medical literature on how specific decisions are made. The rationale for the choice of a specific approach is often not or only scantily addressed. It is known that physicians often utilize a treatment method that was learned during their residency period and often continue with this approach [25]. Furthermore, the surgeon's preference varies between different specialties [25]. Especially in the treatment regimen of this heterogenic disorder, were a multidisciplinary approach is inevitable, all of this may lead to unnecessary interventions and a potential delay in definitive treatment $[7,26]$.

The objective of this study is to present a treatment algorithm based on our experience of airway management in infants with RS. The rationale of specific decisions will be covered. This will provide a comprehensive guidance for a designated treatment strategy and contributes in optimizing the care of infants with RS.

\section{Material and methods}

All infants $<1$ year old diagnosed with RS, who have been treated at the Wilhelmina Children's Hospital Utrecht, The Netherlands, over 16 years (1996-2012), were included in this retrospective cohort study. Ethics committee approval was obtained. RS was defined as signs of airway obstruction and presence of micrognathia. Information about duration of admission and treatment outcome with a follow-up of at least 1 year was extracted from medical records. Moreover, demographic characteristics, performed diagnostics, interventions, and treatment approach were critically analyzed. A subdivision between the nonisolated RS infants (i.e., diagnosis of an additional syndrome related to RS or of other associated anomalies or chromosomal defects not directly related to the features of RS) and isolated RS infants (i.e., only the features of RS without any additional anomaly) was made. Independent samples $t$ test and Mann-Whitney $U$ test were performed (IBM SPSS Statistics 20.0, IBM Inc., New York, USA).

Subsequently, a literature search to find existing algorithms covering the approach to infants with RS was performed. The search was performed in January 2014 without time limits. Similar keywords were used in the Embase, Medline, CINA HL, Cochrane Library, and Google Scholar databases ["(pierre) robin syndrome/sequence" and "algorithm(s)," "approach," "(airway) management," "intervention," "regimen," or "treatment"). Only articles that included a clear description of the patient group, performed examinations, decisional factors, and performed interventions were included. Moreover, concise, state-of-the-art reviews suggesting a treatment approach were included. The bibliographies of the selected studies were handsearched for any additional articles. The search and inclusion process was performed by two authors (E.P. and B.S.).

Finally, the pragmatic approach from our institution is presented in a schematic way.

\section{Results}

\section{Retrospective cohort analyses}

From 1996 to 2012, 75 infants diagnosed with RS were treated in our institution. Baseline characteristics are summarized in Table 1. Mean follow-up was 7.4 years (range, 1-17). Fiftytwo percent $(n=39)$ were female. Seventy-two patients $(97 \%)$ had a cleft palate. The minority of cases $(43 \%, n=32)$ had an isolated form of RS. In one third of the cohort $(31 \%, n=23)$, an associated syndrome was present, Stickler $(n=11,48 \%)$ being the most common. In a quarter $(26 \%, n=20)$, additional anomalies or chromosomal defects were identified, which were not directly related to a syndrome associated with the features of RS.

The majority $(59 \%, n=44)$ of the infants admitted to our hospital could be successfully managed conservatively (Table 2). This consisted of side/prone positioning, temporary supplemental oxygen or usage of continuous positive airway pressure (CPAP), a mayotube or nasopharyngeal airway (NPA) (Fig. 1). In $41 \%(n=31)$, a surgical intervention was pursued, at a mean age of 50 days (SD, 55). Until 2006, this consisted of TLA whenever possible. If TLA failed, or there was a (sub)glottic pathology, a tracheotomy was performed. Since 2006, the primary surgical intervention for UAO caused by a supraglottic obstruction is MDO. During the study period, in more than half of the surgically treated cases $(58 \%, n=18)$, MDO was pursued; in $19 \%(n=$ 6) TLA and in $23 \%(n=7)$, a tracheotomy. Average duration until decannulation after a tracheotomy was 13.4 months (range, 4.1-36.5). More than half of the nonisolated RS infants, compared to only a quarter of the isolated RS, infants needed surgical intervention (53 vs. $25 \%, p=.014$ ) (Table 2 ). 


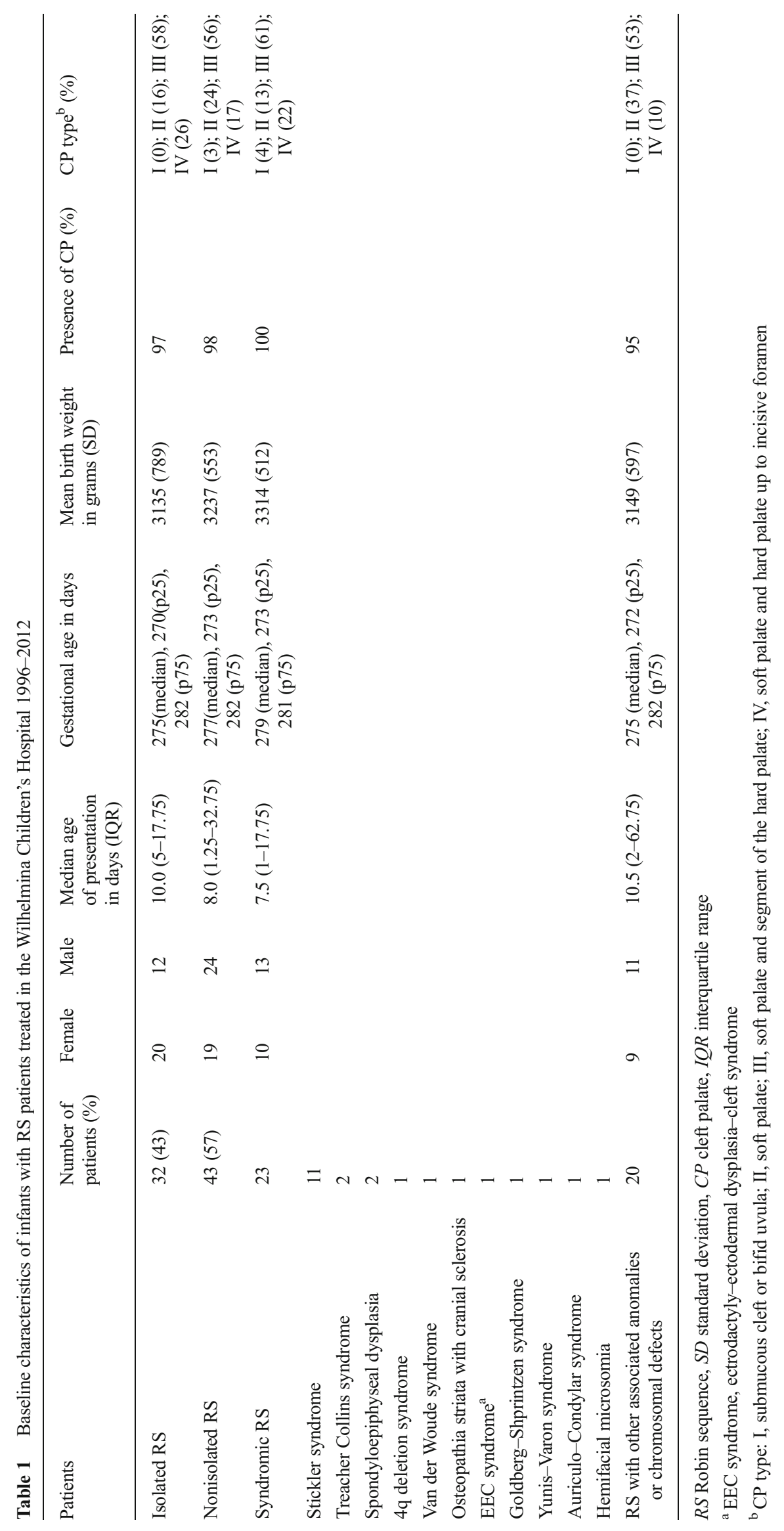


Table 2 Approach to infants with RS treated in the Wilhelmina Children's Hospital 1996-2012

\begin{tabular}{|c|c|c|c|c|}
\hline & Total study group & Isolated RS & Nonisolated RS & $p$ value* \\
\hline Number of patients & 75 & $32(43 \%)$ & $43(57 \%)$ & \\
\hline Conservative treatment $^{\mathrm{a}}$ & $44(59 \%)$ & $24(75 \%)$ & $20(47 \%)$ & 0.014 \\
\hline Surgical treatment ${ }^{\mathrm{b}}$ & $31(41 \%)$ & $8(25 \%)$ & $23(53 \%)$ & 0.014 \\
\hline MDO & 18 & 6 & 12 & \\
\hline TLA & 6 & 1 & 5 & \\
\hline Tracheotomy & 7 & 1 & 6 & \\
\hline Mean age at surgical intervention in days (SD) & $50(55)$ & $57(42)$ & $47(60)$ & 0.620 \\
\hline Mean duration of admission in days $(\mathrm{SD})^{\mathrm{c}}$ & $48(43)$ & $33(35)$ & $58(45)$ & 0.018 \\
\hline Conservatively treated group (SD) & $30(30)$ & $24(32)$ & $35(27)$ & 0.285 \\
\hline Surgically treated group (SD) & $73(46)$ & $55(35)$ & $80(48)$ & 0.163 \\
\hline Nasogastric tube & 58 & $20(63 \%)$ & $38(88 \%)$ & 0.009 \\
\hline
\end{tabular}

$M D O$ mandibular distraction osteogenesis, TLA tongue lip adhesion, $S D$ standard deviation

${ }^{*} p<0.05$ was considered statistically significant

${ }^{\text {a }}$ Side or prone positioning, supplemental oxygen, mayotube, or nasopharyngeal airway

${ }^{\mathrm{b}}$ The first surgical intervention was counted

${ }^{\mathrm{c}}$ Total duration of all hospital admissions related to airway or feeding problems in the first year of age

Moreover, mean duration of admission was significantly shorter in the isolated group than in the nonisolated group (33 vs. 58 days, $p=.018$ ). Two infants with syndromic RS received

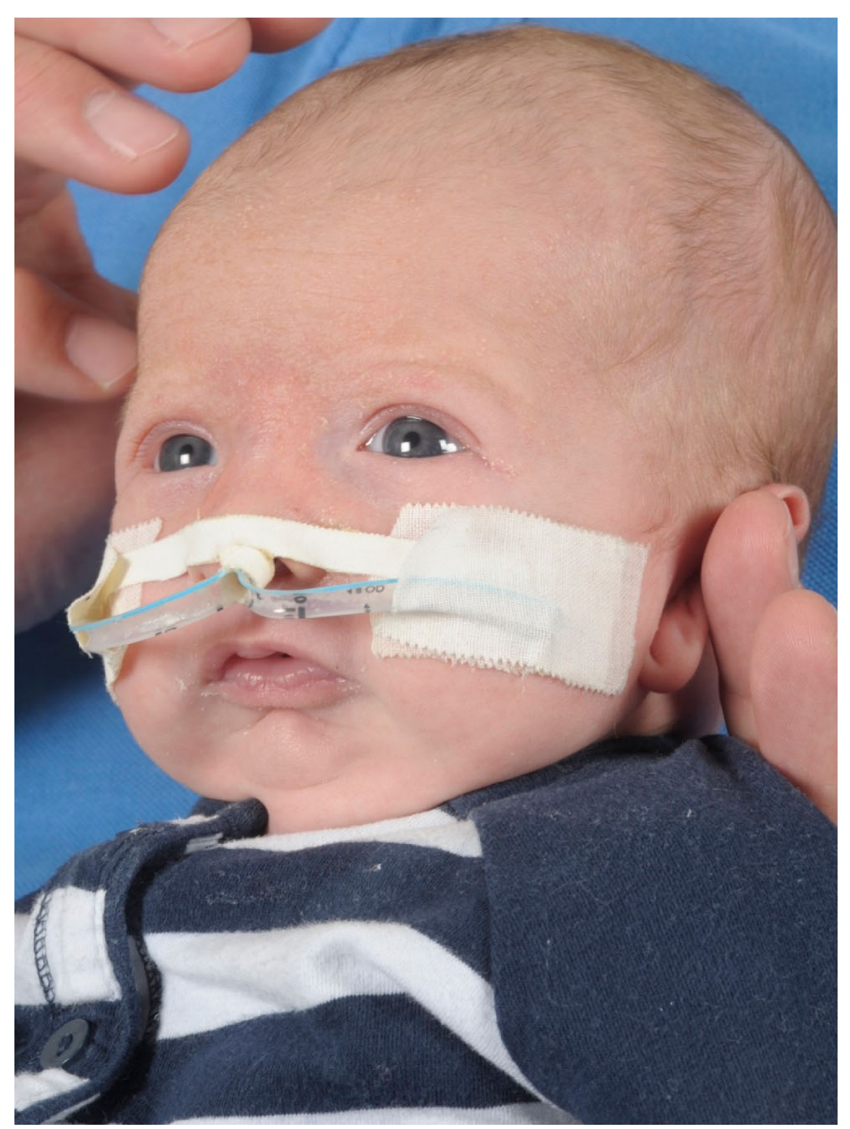

Fig. 1 Use of a nasopharyngeal airway as conservative treatment option in a 1-month-old infant with RS two interventions: One patient had a tracheotomy prior to MDO; another needed a tracheotomy directly after release of the TLA. Both were successfully decannulated afterwards.

Seventy-seven percent of all infants received temporary nasogastric (NG)-tube feeding during an average of 247 days. Average duration of NG-tube feeding was significantly longer in the surgically treated group than in the conservative treated group (resp. median: 72 days; mean rank: 30.5 vs. median: 21 days mean rank: 19.7, $p=.008$ ). Presence of NG-tube feeding showed a highly significant relation with mean duration of admission $(p=.000)$; patients who had received NG-tube feeding were longer admitted in the hospital (44.2 days; SD, 39.1) as compared to patients who had not received NG-tube feeding (4.1 days; SD, 3.6).

Fourteen infants needed temporarily endotracheal intubation prior to surgical intervention, due to severe respiratory distress. Eleven were successfully extubated after surgery. Six infants (8\%), all syndromic RS, ultimately died due to cardiac or pulmonary pathology at a mean age of 416 days (44 days3 years). All had been immediately intubated within several days after birth. One child was diagnosed with $4 \mathrm{q}$ deletion syndrome and received a TLA 23 days after birth and, subsequently, a tracheostomy 52 days after birth. He died due to a cardiac arrhythmia 10 months after the surgery. An infant with Yunis-Varon syndrome underwent TLA after 20 days but could not be extubated, and ultimately died after 41 days due to severe respiratory obstruction. Another infant with Treacher Collins who was primarily treated successfully with MDO 2 weeks after birth, died at almost 2 years of age due to aspiration pneumonia. A child with spondyloepiphyseal dysplasia died 44 days after a tracheotomy due to cardiac failure. Another child with psychomotor retardation, recurrent feeding difficulties, and an atrial and ventricle septum defect died possibly due to a cardiac 
problem at the age of 9 months. At the request of the parents, no autopsy was performed. Finally, a patient with severe psychomotor retardation, blindness, epilepsia, gastroesophageal reflux, and recurrent pneumonias died at 3 years of age due to sepsis en respiratory insufficiency after an aspiration pneumonia.

\section{Literature review}

The literature search yielded a total of 393 articles. Duplicates were excluded, and abstracts were further analyzed for relevance. Five literature studies [7, 9, 16, 27, 28], 25 retrospective case studies $[8,10,14,19,20,29-48]$ and one prospective cohort study [49] fulfilled our selection criteria and were included for further analysis. There was final agreement between the two authors regarding the inclusion process. A summary of the approach described in these articles is listed in Table 3.

\section{Wilhelmina Children's Hospital approach}

Our treatment algorithm is presented in Fig. 2. Infants diagnosed with RS are initially treated in prone or side position when their condition allows it. Prior to any decision making, the patient is observed for at least $24 \mathrm{~h}$. Monitoring of vital parameters, measurements of oxygen saturation by continuous pulse oximetry, capillary blood gas analysis, and more recently transcutaneous carbon dioxide measurements $\left(\operatorname{Tosca}^{\circledR}\right)$ are performed [50-52]. Observation of clinical signs of respiratory distress during sleep and awake, as well as feeding ability, are documented by experienced nursing and medical staff. We consider oxygen saturations of $<90 \%$ for $>5 \%$ of the monitored time and/or any single desaturation $<80 \%$ as a sign of UAO $[39,41,42]$. Blood gas analysis revealing respiratory acidosis $\left(\mathrm{pCO}_{2}>50 \mathrm{mmHg}, \mathrm{HCO}_{3}>30 \mathrm{mmHg}\right.$ ) or transcutaneous $\mathrm{CO}_{2}>50 \mathrm{mmHg}$ during $>25 \%$ of the total sleep time is indicative of hypoventilation [53]. Results are discussed in a multidisciplinary setting consisting of at least a pediatrician, plastic surgeon, otolaryngologist, and a pediatric intensive care specialist after $24-48 \mathrm{~h}$ of monitoring. A clinical geneticist is always consulted. Based on the observations and measurements, patients are divided into mild UAO or moderate/severe UAO. These characteristics are described in Fig. 2.

Patients with RS with mild UAO remain closely monitored in prone or side position (Fig. 2). Depending on the clinical condition, measurements are repeated and reassessed. Poor weight gain is defined as $<150 \mathrm{~g} /$ week [41]. In these cases, further analysis by a pediatrician is indicated, and NG-tube feeding may be necessary $[37,54]$. If the before-mentioned measurements remain normal, patients will be discharged after the parents are sufficiently instructed. Pulse oximetry is continued at home for an average of 3 months, and at least once a month, the pediatric outpatient department is visited.

In moderate to severe $U A O$, the location of the airway obstruction should be investigated by direct flexible laryngoscopy to localize the site of obstruction and to identify possible other airway comorbidities that would influence the decision-making process [55] (Fig. 2). True glossoptosis or other supraglottic obstruction can be diagnosed by this measure (Fig. 3). If the clinical symptoms cannot or only partially be explained by the visible airway obstruction, an overnight polysomnography (PSG) is warranted. Hereby, central apneas, mixed apneas, or episodes of obstructive apnea can be diagnosed, as the glossoptosis tends to be a dynamic problem and could not be identified with laryngoscopy. If substantial central or mixed apnea is detected, a specialist in pulmonary or sleep medicine is consulted. Once the diagnosis of a supraglottic/tongue base obstruction is made, an NPA or mayotube is inserted to maintain a patent airway, and the infant is closely monitored. It is important to mention that other options for conservative treatment, such as orthopedic appliances (like palatal plates or the pre-epiglottic baton plate), have been described to date [12-14]. However, these are not implemented in our algorithm as we are currently not familiar with the use of it in our institution. In the most severe cases of UAO (i.e., micrognathia with severe clinical signs of respiratory obstruction, any single desaturation $<80 \%$ or severe respiratory acidosis despite positioning) immediate MDO or TLA could be anticipated. However, in our institution, we advocate a trial period of NPA prior to any surgical measure. Depending on the clinical condition of the infant, the case is then reassessed in our team after several days of continuous and cautious monitoring. If earliermentioned measurements and observations are normal and the infant shows sufficient weight gain, NPA treatment will be continued. If the infant shows deterioration despite NPA, the surgical options will be discussed with the parents. Until 2006, either TLA or tracheotomy was performed. However, after 2006, MDO has become our surgical procedure of preference when a supraglottic obstruction and a true micrognathia together with a normal functioning temporomandibular joint are present [56]. Before surgery is pursued, other pathology should be ruled out by flexible laryngotracheobronchoscopy. Moreover, radiological assessment of the mandible with a lateral X-ray or CT scan is obtained (Fig. 4). Our performed technique with a resorbable internal distraction apparatus has been described previously $[23,24]$. Occasionally, when patients do not have a very small mandible but evident glossoptosis is present, TLA is performed. Still, as it is difficult to accurately assess the mandibular size in infants, often, both procedures and their (dis)advantages are discussed in our team and with the parents. After surgery, vital parameters and blood gasses with pulse oximetry should be regular reassessed.

In our cohort, 29 infants (39\%) suffered mild RS according to our classification. Of these, four (14\%) had to be subsequently treated according the moderate/severe limb of the algorithm, of whom one patient ultimately received a tracheostomy. Forty-six $(61 \%)$ of the admitted infants were initially classified as moderate/severe RS and treated accordingly. Of these, 30 infants ( $47 \%$ ) were treated surgically. 


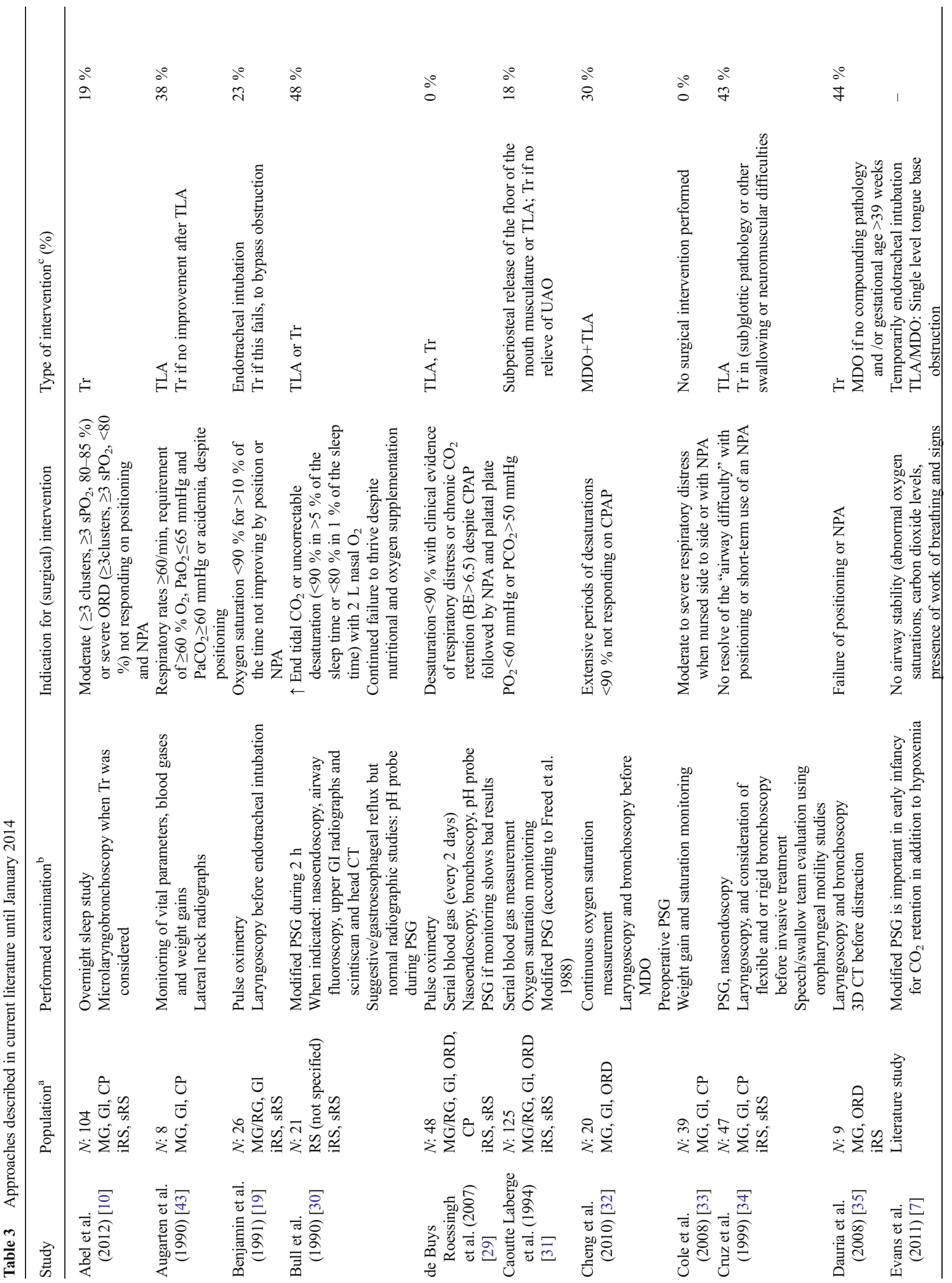




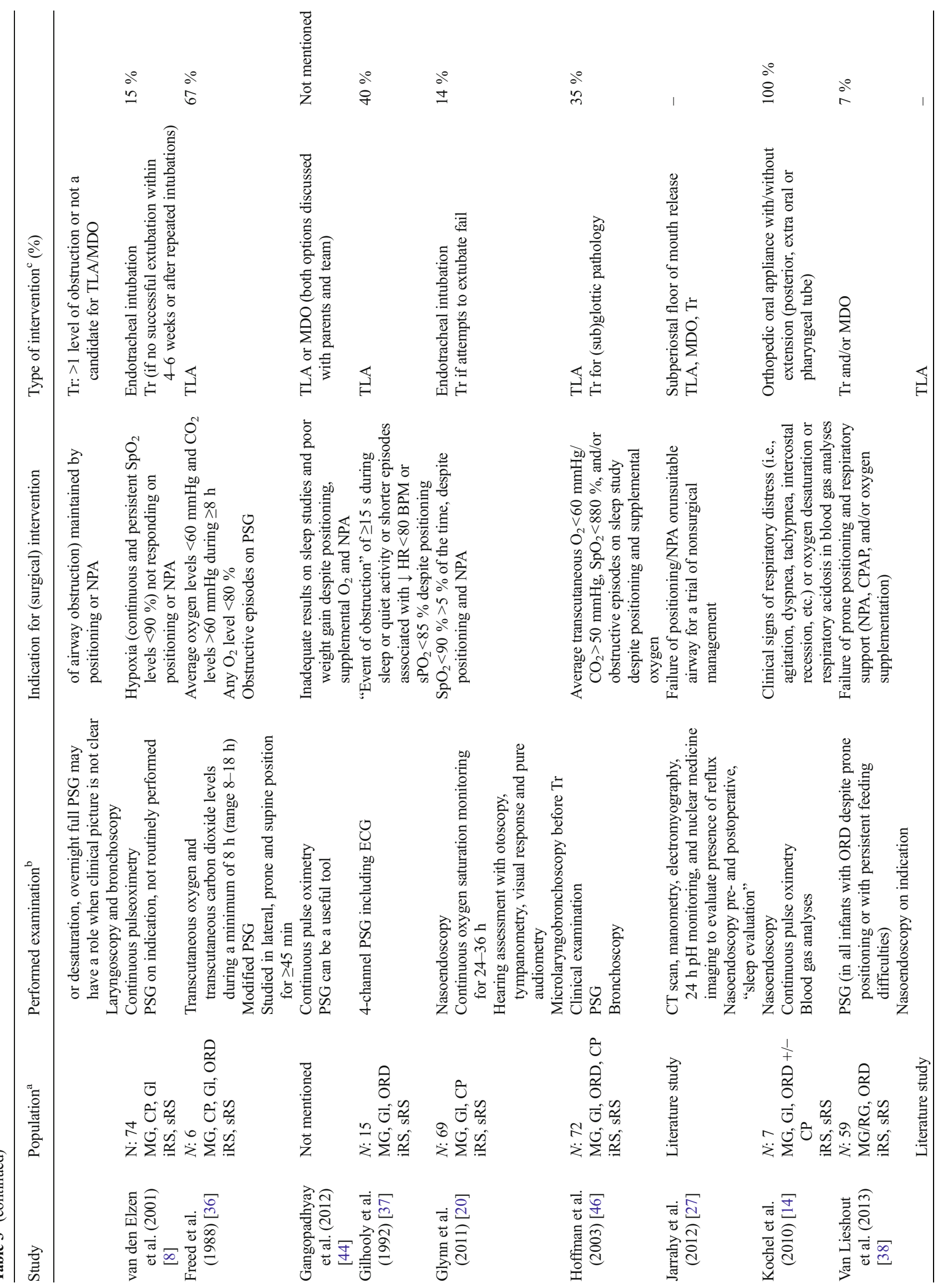




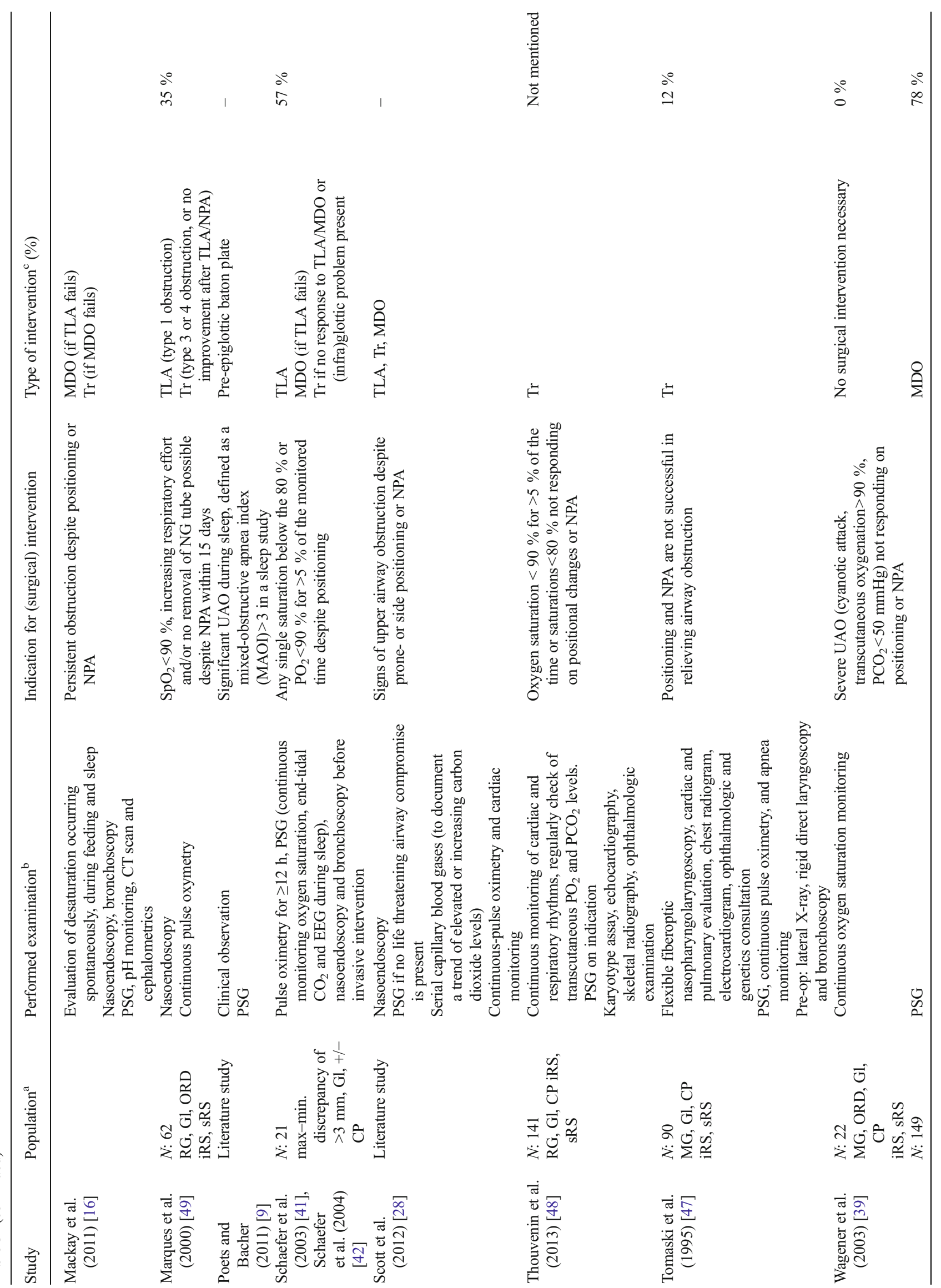




\section{Discussion}

The current study was performed due to the paucity of treatment algorithms for infants with RS in the literature. A plethora of different treatment modalities is suggested, but decisions and rational on which the interventions are based are variable and often ambiguous. A more standardized approach to this challenging clinical entity should be used. An efficient strategy with a multidisciplinary approach might decrease mortality and morbidity, as possible respiratory and feeding problems may be more quickly recognized and treated more efficient [31]. By a thorough retrospective analysis of the treatment regime in our institution and a review of the current literature, we have developed recommendations in the form of an algorithm, which could be applied as a guidance for other centers involved in the care for infants with RS.

The understanding of RS is among others hampered by the numerous different definitions that are used to describe this condition [26, 57-59]. Most authors of the analyzed studies use the criteria described by Pierre Robin in 1934, thus presence of micrognathia, glossoptosis, respiratory distress, and a cleft palate (Table 3) [2]. According to others, in our institution, we define the disorder as presence of micrognathia combined with signs of UAO [38]. Sometimes, we encounter difficulty in determining glossoptosis, possibly due to the fact that intra-oral inspection does not immediately have to reveal its presence and no easy applicable scale of measurement exists. Glossoptosis can be a dynamic problem in which the degree of "ptosis" of the tongue, and subsequent upper airway obstruction, varies, depending on the position and state of the infant (for example asleep, during feeding or tired). Moreover, UAO in patients with micrognathia does not necessarily indicate glossoptosis, since other or additional causes for airway obstruction might be present (e.g., neurologic abnormalities, pharyngeal hypotonia, or choanal atresia) in $\operatorname{RS}[3,55]$. Therefore, we advice to perform a flexible laryngoscopy in cases with moderate/severe UAO to quickly obtain more information about this matter (Fig. 3). Endoscopic findings in RS have been clearly described and graded [55]. Finally, the presence of a cleft palate is not obligatory for the diagnosis, although it was encountered in $97 \%$ of our patients $[9,44]$.

A common understanding in the literature is to start every treatment of an RS patient with conservative measures. In our series, more than half of the infants $(59 \%, n=44)$ could be treated conservatively, which is comparable to others [30, 32, $34,35,37,49]$. Conservative treatment usually starts with prone or side positioning, which will reduce airway obstruction at tongue base level by allowing the mandible and tongue to fall forward. Some do advocate side positioning, since prone positioning might obscure signs of respiratory distress and makes it difficult for the parents to interact with their baby [33]. Supplemental oxygen can be provided when necessary by a nasal cannula. When positioning fails, use of an NPA, 


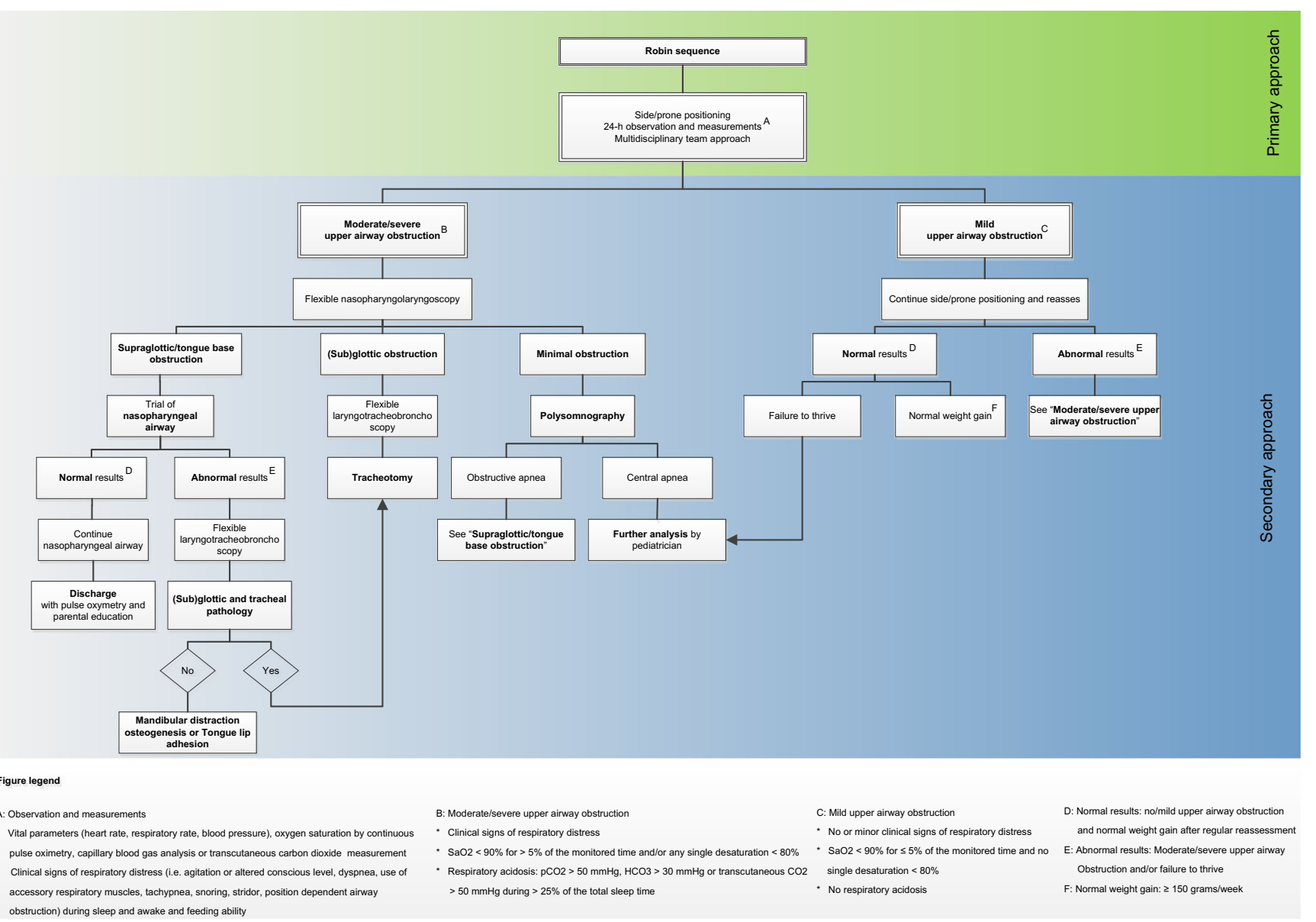

Fig. 2 Algorithm of the institutional approach to infants with Robin sequence

mayotube, or CPAP are frequently described secondary measures (Table 3). NPA has obtained a lot of interest and revealed good results (Fig. 1) [10, 29, 33, 39]. According to our approach, the majority of the authors starts using an NPA when positioning fails $[8,10,16,19,20,27-29,33-35,38-40,44$, 45, 47-49]. As we have obtained feasible results, we currently

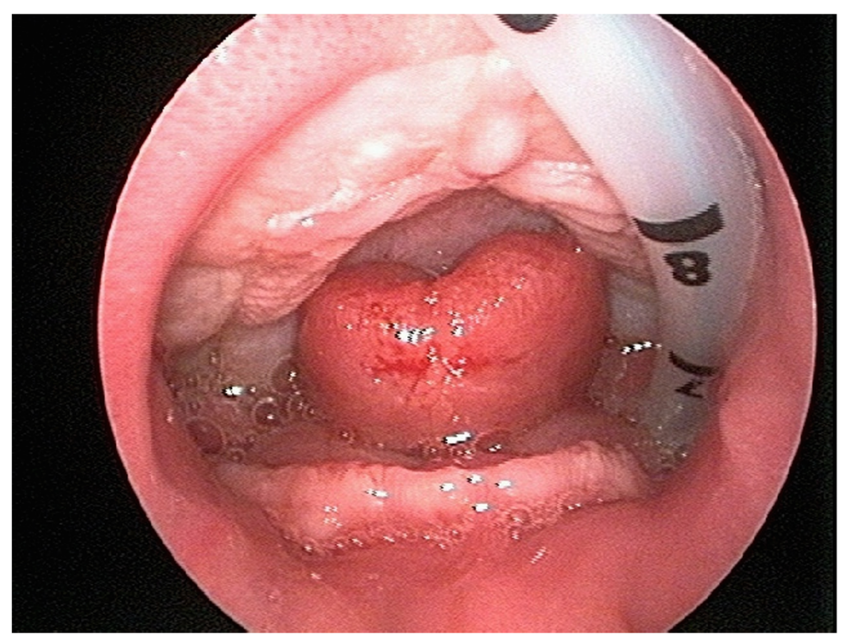

Fig. 3 Example of glossoptosis evaluated by direct flexible laryngoscopy use NPA in every infant with significant UAO before a surgical measure is initiated, and no longer apply a mayotube or CPAP. Yet, the exact place of CPAP still needs to be defined in the treatment of RS. Certain drawbacks of NPA are known. Duration of treatment, obstruction, or luxation of the tube, the burden of care for the parents when the child is discharged with NPA, and persistent feeding problems during the treatment have been described [10,60]. Finally, also other conservative options, such as the custom-made palatal plate or preepiglottic baton plate (PEBP), have been described to date [12,

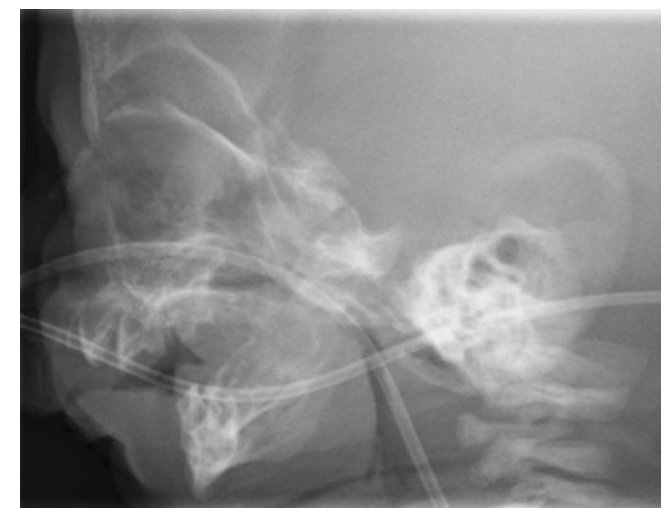

Fig. 4 Example of micrognathia seen on lateral X-ray 
$14,15]$. The promising results of a velar extension in the PEBP have been demonstrated in a randomized clinical trial regarding isolated RS infants [15]. It has also revealed positive effects on feeding issues [61]. The PEBP might completely obviate the necessity of a surgical intervention, by noninvasively moving the base of the tongue forward and subsequently widening the oropharynx. It is speculated that this protrusion of the tongue might also stimulate mandibular growth, although this has not yet been proven [13]. Still, when using these orthopedic appliances, it is necessary to have an experience team, including skilled nurses who can guide and train parents in handling the PEBP [9]. As demonstrated in the literature, the training during residency is of paramount importance regarding what technique will be utilized in the institution [25]. However, the country and the supporting medical system will also influence the decision making in what the most useful conservative treatment option will be.

The percentage of infants that need invasive treatment differs from 0 to $78 \%[14,29,33,39,40,45]$ in medical literature (Table 3). These varying percentages are illustrative of the difficulty to accurately define at which exact point the infant fails to respond to conservative treatment and a surgical intervention is anticipated. Many authors tend to use cut-off values derived from specific tests such as PSG or blood measurements to determine candidacy for surgery $[10,19,20$, 29-32, 36, 37, 39, 41, 42, 44, 46, 47] (Table 3). While we also take account of oxygen saturations and $\mathrm{CO}_{2}$ levels, we strongly recommend that the multidisciplinary team considers all available results including clinical observation and feeding status, when deciding about escalating care (Fig. 2). Standard usage of PSG in the management of RS remains a point of discussion [7, 28, 29, 37, 62]. In accordance to others and as demonstrated in the flowchart, in our institution, PSG is only performed on indication, to exclude central apneas or to quantify more subtle airway obstruction if the clinical symptoms cannot or only partially be explained by the visible airway obstruction (Fig. 2) [7, 19, 20, 29, 37, 39] In the majority of the studies that used PSG routinely, a so-called "modified PSG" is performed using only certain components of PSG $[31,32,36,37,41,42,46]$. It is mandatory that important matters such as the exact indication, frequency, and the extensiveness of the conducted tests on PSG are clarified in further studies, and strict recommendations for its use can be made.

Forty-one percent of the infants of our cohort needed a surgical intervention, comparable to findings described by others [29, $30,34,35,37,43,46]$. In the analyzed literature, surgical interventions consist mainly of TLA [20, 28-31, 34, 36, 37, 41-43, 46, 49] or MDO when TLA failed [16, 41, 42] (Table 3). Some recommended MDO as primary measure $[35,40,45]$ or a combination of MDO and TLA [32]. Generally, tracheotomy was considered as final option when there was no improvement after TLA and/or MDO [7, 16, 27, 28, 31, 34, 35, 41-43, 46, 49]. Other indications were the presence of a central neurological impairment or coinciding upper airway [i.e. (sub)glottic obstruction or tracheo- or laryngomalacia], cardiac, pulmonary, or gastroesophageal pathology, contributing to the respiratory distress $[7,27,28,30,34,35,40-42,44,46]$. Still, some authors choose tracheotomy as the primary surgical strategy after conservative treatment has failed [10, 19, 20, 47, 48, 63]. In our series, MDO was the primary choice in more than half of the surgically treated cases (Table 2). Until 2006, TLA was our surgical procedure of preference with subsequent tracheotomy if TLA failed or could not be performed due to (sub)glottic pathology. At this moment, we only perform TLA in the rare cases where patients have an obvious glossoptosis without clear micrognathia. Objectively assessing the size of micrognathia is not easy, and currently, the (dis)advantages of both MDO and TLA are discussed in a multidisciplinary team meeting and with the parents. It is important to emphasize the risk of glossoptosis recurring after TLA release [64]. MDO also proves to be more effective than TLA in resumption of normal oral feeding [65]. In our series, all children could bottle feed within 4 weeks after distraction and NG-tube feeding could be stopped [24]. Additionally, since we use a resorbable distracting system, there is no need for a second intervention, while patients with TLA need secondary surgery to release the adhesion [24]. Finally, there is less scar formation after MDO [66]. However, long-term follow-up studies after MDO in RS patients are still scarce. Furthermore, possible damage to the permanent molars in the osteotomy region and mandibular outgrow after MDO remains a point of investigation and discussion. In order to clarify these matters, analyses are currently undertaken at our institution.

Six infants ( $8 \%$ ) of our cohort, all nonisolated RS patients, died after a mean of 416 days ( 44 days -3 years). Reported mortality rates in the literature vary from 0 up to $26 \%$ [8]. It is important to realize that RS is a heterogenic disorder with numerous causes and also possible co-morbidities, which can aggravate the already present symptoms [44]. An additional syndrome or malformation makes the treatment regime especially challenging and a multidisciplinary approach indispensable. In $75 \%$ of the infants with isolated RS, conservative measures revealed to be sufficient to maintain an adequate airway. In contrast, of the nonisolated infants, only $47 \%$ could be treated conservatively (Table 2 ). This important, significant finding $(p=0.014)$ demonstrates the relevance of adequate and early genetic analysis. Less favorable airway outcomes are more common in nonisolated RS, potentially attributed to airway and swallowing problems independent of glossoptosis [28, 31, 47, 67]. In addition, mandibular size and morphology vary significantly in syndromic RS [68]. Although we are aware that an associated syndrome could have important consequences for the long-term mandibular outgrowth, this does not influence our initial treatment approach, as the respiratory distress still needs to be treated and will be alleviated by advancing the mandible. However, MDO or other surgical interventions should only be considered after other or additional 
etiologies of respiratory compromise (such as tracheo-or laryngeomalacia) are ruled out. Furthermore, it needs to be addressed that conservative measures can obtain good results and should always be performed in first instance, also in syndromic RS infants [14].

It is still not fully elucidated what risk factors exist and which infants have an absolute contraindication to receive surgery. Murage and co-workers reviewed the results of 50 infants who were treated with MDO and concluded that the absence of a CP, presence of gastroesophageal reflux, and need for Nissen fundoplication might be associated with failure of MDO [69]. Prematurity, low birth weight, late operation, preoperative intubation, diagnosis of a syndrome, and cardiac and pulmonary abnormalities did not preclude success in appropriately selected patients [69]. On the contrary, others demonstrated that, besides gastroesophageal reflux, also preoperative intubation, late operation (older than 2 weeks), low birth weight, and diagnosis of a syndrome were significant predictive markers of failure of TLA and necessity of a tracheotomy $[67,70]$. The cited studies are retrospective and may contain substantial bias. Prospective studies, systematically collecting data, are needed to understand risk factors for failure and success of interventions and to develop evidenced based clinical guidelines to facilitate treatment planning.

Besides the airway problems, feeding difficulties are also a common finding in infants with RS and should be adequately supported [7, 71]. Seventy-seven percent $(n=58)$ of the infants in our series needed NG-tube feeding during an average of 247 days. This comprised of significantly more infants of the nonisolated group ( $88 \%$ ), compared to $63 \%$ of the isolated RS patients $(p=.009)$. Duration of NG-tube feeding was also significantly shorter in the conservative treated group $(p=.008)$. However, in all cases after MDO, NG-tube feeding could be successfully stopped within 4 weeks postoperatively, independent of the syndromic or nonsyndromic status. Feeding difficulties in RS can have multiple causes [61], on the one hand attributed to the micrognathia, glossoptosis, or the possible concomitant cleft palate, and also to possible additional upper digestive tract motor dysfunction, leading to esophageal motility disorders or reflux disease. Associated cardiac or other complex abnormalities can also lead to compromised growth [7]. In persistent feeding problems, we advice consulting a pediatrician or pediatric neurologist to rule out other pathology.

One of the strengths of the current study is that it gives a clear insight of the treatment in a relatively large cohort of infants with RS, and a structured and pragmatic algorithmic approach including the rationale of the decisions taken. This could be used as guidance in other institutions. Moreover, it provides a clear overview of approaches described in the literature. Limitations include a possible selection bias as this is a tertiary center. In addition, the retrospective nature of the study and the relatively short follow-up period should be emphasized. Finally, we are fully aware that our approach could differ from the supporting medical system and regional habits of other institutions. Other treatment options, such as orthopedic appliances, have been described in the current literature yielding very good results $[9,13,14]$. Yet, in our institution, we do not have experience in using them. However, this does not preclude their beneficial use in infants with RS in other practices.

It should be addressed that many different treatment options could probably be performed on a patient. Each intervention has known (dis)advantages and the outcome depends on multiple factors. Burden of care, treatment duration, long-term complications, and financial implications should be considered [65, 66, $72,73]$. Furthermore, surgical skills and preferences will influence the approach of the treatment center [25]. It is demonstrated that mortality and morbidity are significantly lower in infants treated by the use of a decisional model $[40,45]$. However, the choice of a specific treatment for an infant with RS is a continuous and dynamic process, with multiple factors to be regarded and with many caretakers involved. The algorithm, as presented in the current study, should be used as a guideline and not as a rigid decision tree since every patient is unique. Still, using an algorithm, we hope to prevent possible unnecessary proceedings and a potential delay in treatment by helping involved caretakers in decision making. Prospective studies will give us more insight in the outcome of the different strategies, which unfortunately do not exist to date. Using an algorithm, it might be easier to compare the outcome of the different modalities in the nearby future.

\section{Conclusion}

RS is a heterogeneous disorder with numerous different treatment strategies described to date. A pragmatic approach is presented in this manuscript. The management of RS involves a multidisciplinary team approach to achieve a safe airway and adequate growth. We hope that this manuscript will serve as a guidance for caretakers involved in the care for infants with RS and as an impetus for conducting future (preferably prospective) studies.

Acknowledgments The authors thank Mr. Victor H.C. van den Berg for his technical support in the design of the algorithm and Mr. Gregory Hayles for his assistance in English grammar and language.

Conflict of interest No conflicts of interest to disclose by any author.

Funding source No funding was secured for this study.

Financial disclosure No financial relationships relevant to this article to disclose.

Open Access This article is distributed under the terms of the Creative Commons Attribution License which permits any use, distribution, and reproduction in any medium, provided the original author(s) and the source are credited. 


\section{References}

1. Robin P (1923) La chute de la base de la langue considérée comme une nouvelle cause de gans la respiration naso-pharyngienne. Bull Acad Natl Med 89:37-41

2. Robin P (1934) Glossoptosis due to atresia and hypotrophy of the mandible. Am J Dis Child 48:541-547

3. Shprintzen RJ (1992) The implications of the diagnosis of Robin sequence. Cleft Palate Craniofac J 29:205-209

4. Vatlach S, Maas C, Poets CF (2014) Birth prevalence and initial treatment of Robin sequence in Germany: a prospective epidemiologic study. Orphanet J Rare Dis 9:9-1172-9-9

5. Bush PG, Williams AJ (1983) Incidence of the Robin Anomalad (Pierre Robin syndrome). Br J Plast Surg 36:434-437

6. Printzlau A, Andersen M (2004) Pierre Robin sequence in Denmark: a retrospective population-based epidemiological study. Cleft palate. Craniofac J 41:47-52

7. Evans KN, Sie KC, Hopper RA et al (2011) Robin sequence: from diagnosis to development of an effective management plan. Pediatrics 127:936-948

8. van den Elzen AP, Semmekrot BA, Bongers EM et al (2001) Diagnosis and treatment of the Pierre Robin sequence: results of a retrospective clinical study and review of the literature. Eur J Pediatr $160: 47-53$

9. Poets CF, Bacher M (2011) Treatment of upper airway obstruction and feeding problems in Robin-like phenotype. J Pediatr 159:887892

10. Abel F, Bajaj Y, Wyatt M et al (2012) The successful use of the nasopharyngeal airway in Pierre Robin sequence: an 11-year experience. Arch Dis Child 97:331-334

11. Mondini CC, Marques IL, Fontes CM et al (2009) Nasopharyngeal intubation in Robin sequence: technique and management. Cleft Palate Craniofac J 46:258-261

12. Butow KW, Hoogendijk CF, Zwahlen RA (2009) Pierre Robin sequence: appearances and 25 years of experience with an innovative treatment protocol. J Pediatr Surg 44:2112-2118

13. Bacher M, Sautermeister J, Urschitz MS et al (2011) An oral appliance with velar extension for treatment of obstructive sleep apnea in infants with pierre robin sequence. Cleft Palate Craniofac J 48:331-336

14. Kochel J, Meyer-Marcotty P, Wirbelauer J et al (2011) Treatment modalities of infants with upper airway obstruction - review of the literature and presentation of novel orthopedic appliances. Cleft Palate Craniofac J 48:44-55

15. Buchenau W, Urschitz MS, Sautermeister J et al (2007) A randomized clinical trial of a new orthodontic appliance to improve upper airway obstruction in infants with Pierre Robin sequence. J Pediatr 151:145-149

16. Mackay DR (2011) Controversies in the diagnosis and management of the Robin sequence. J Craniofac Surg 22:415-420

17. Bijnen CL, Don Griot PJ, Mulder WJ et al (2009) Tongue-lip adhesion in the treatment of Pierre Robin sequence. J Craniofac Surg 20: 315-320

18. Mokal NJ, Desai MF and Sawant P (2014) Reinventing the technique of tongue-lip adhesion in Pierre Robin sequence. J Plast Reconstr Aesthet Surg 67(3):415-417

19. Benjamin B, Walker P (1991) Management of airway obstruction in the Pierre Robin sequence. Int J Pediatr Otorhinolaryngol 22:29-37

20. Glynn F, Fitzgerald D, Earley MJ et al (2011) Pierre Robin sequence: an institutional experience in the multidisciplinary management of airway, feeding and serous otitis media challenges. Int J Pediatr Otorhinolaryngol 75:1152-1155

21. Breugem CC, Olesen PR, Fitzpatrick DG et al (2008) Subperiosteal release of the floor of the mouth in airway management in Pierre Robin sequence. J Craniofac Surg 19:609-615
22. Caouette-Laberge L and Borsuk DE. (2012) Subperiosteal release of the floor of the mouth to correct airway obstruction in Robin sequence: review of 31 cases. Cleft Palate Craniofac J 49(1):14-20

23. Burstein FD, Williams JK (2005) Mandibular distraction osteogenesis in Pierre Robin sequence: application of a new internal singlestage resorbable device. Plast Reconstr Surg 115:61-67, discussion 68-9

24. Breugem C, Paes E, Kon M et al (2012) Bioresorbable distraction device for the treatment of airway problems for infants with Robin sequence. Clin Oral Investig 16:1325-1331

25. Collins B, Powitzky R, Robledo C et al (2014) Airway management in Pierre Robin sequence: patterns of practice. Cleft Palate Craniofac J 51(3):283-289

26. Basart H, Kruisinga FH, Breugem CC et al (2015) Will the right Robin patient rise, please? Definitions and criteria during management of Robin sequence patients in The Netherlands and Belgium. J Craniomaxillofac Surg 43(1):92-96

27. Jarrahy R (2012) Controversies in the management of neonatal micrognathia: to distract or not to distract, that is the question. $\mathrm{J}$ Craniofac Surg 23:243-249

28. Scott AR, Tibesar RJ, Sidman JD (2012) Pierre Robin sequence: evaluation, management, indications for surgery, and pitfalls. OtolaryngolClinNorth Am 45:695-710

29. de Buys Roessingh AS, Herzog G, Hohlfeld J (2007) Respiratory distress in Pierre Robin: successful use of pharyngeal tube. J Pediatr Surg 42:1495-1499

30. Bull MJ, Givan DC, Sadove AM et al (1990) Improved outcome in Pierre Robin sequence: effect of multidisciplinary evaluation and management. Pediatrics 86:294-301

31. Caouette-Laberge L, Bayet B, Larocque Y (1994) The Pierre Robin sequence: review of 125 cases and evolution of treatment modalities. Plast Reconstr Surg 93:934-942

32. Cheng AT, Corke M, Loughran-Fowlds A et al (2011) Distraction osteogenesis and glossopexy for Robin sequence with airway obstruction. ANZ J Surg 81:320-325

33. Cole A, Lynch P, Slator R (2008) A new grading of Pierre Robin sequence. Cleft Palate Craniofac J 45:603-606

34. Cruz MJ, Kerschner JE, Beste DJ et al (1999) Pierre Robin sequences: secondary respiratory difficulties and intrinsic feeding abnormalities. Laryngoscope 109:1632-1636

35. Dauria D, Marsh JL (2008) Mandibular distraction osteogenesis for Pierre Robin sequence: what percentage of neonates need it? J Craniofac Surg 19:1237-1243

36. Freed G, Pearlman MA, Brown AS et al (1988) Polysomnographic indications for surgical intervention in Pierre Robin sequence: acute airway management and follow-up studies after repair and take-down of tongue-lip adhesion. Cleft Palate J 25:151-155

37. Gilhooly JT, Smith JD, Howell LL et al (1993) Bedside polysomnography as an adjunct in the management of infants with Robin sequence. Plast Reconstr Surg 92:23-27

38. van Lieshout MJ, Joosten KF, Hoeve HL et al (2014) Unravelling Robin sequence: considerations of diagnosis and treatment. Laryngoscope 124(5):E203-9

39. Wagener S, Rayatt SS, Tatman AJ et al (2003) Management of infants with Pierre Robin sequence. Cleft Palate Craniofac J 40:180-185

40. Vyas RM, Dipple KM, Head C et al (2008) Management of neonatal upper airway obstruction: decreased morbidity by utilizing a decision tree model with mandibular distraction osteogenesis. J NeonatalPerinatal Med 1:21-29

41. Schaefer RB, Gosain AK (2003) Airway management in patients with isolated Pierre Robin sequence during the first year of life. J Craniofac Surg 14:462-467

42. Schaefer RB, Stadler JA 3rd, Gosain AK (2004) To distract or not to distract: an algorithm for airway management in isolated Pierre Robin sequence. Plast Reconstr Surg 113:1113-1125 
43. Augarten A, Sagy M, Yahav J et al (1990) Management of upper airway obstruction in the Pierre Robin syndrome. Br J Oral Maxillofac Surg 28:105-108

44. Gangopadhyay N, Mendonca DA, Woo AS (2012) Pierre Robin sequence. Semin Plast Surg 26:76-82

45. Kohan E, Hazany S, Roostaeian J et al (2010) Economic advantages to a distraction decision tree model for management of neonatal upper airway obstruction. Plast Reconstr Surg 126:1652-1664

46. Hoffman W (2003) Outcome of tongue-lip plication in patients with severe Pierre Robin sequence. J Craniofac Surg 14:602-608

47. Tomaski SM, Zalzal GH, Saal HM (1995) Airway obstruction in the Pierre Robin sequence. Laryngoscope 105:111-114

48. Thouvenin B, Djadi-Prat J, Chalouhi C et al (2013) Developmental outcome in Pierre Robin sequence: a longitudinal and prospective study of a consecutive series of severe phenotypes. Am J Med Genet A 161A:312-319

49. Marques IL, de Sousa TV, Carneiro AF et al (2001) Clinical experience with infants with Robin sequence: a prospective study. Cleft Palate Craniofac J 38:171-178

50. Kirk VG, Batuyong ED, Bohn SG (2006) Transcutaneous carbon dioxide monitoring and capnography during pediatric polysomnography. Sleep 29:1601-1608

51. Tobias JD (2009) Transcutaneous carbon dioxide monitoring in infants and children. Paediatr Anaesth 19:434-444

52. Tobias JD, Meyer DJ (1997) Noninvasive monitoring of carbon dioxide during respiratory failure in toddlers and infants: end-tidal versus transcutaneous carbon dioxide. Anesth Analg 85:55-58

53. Berry RB, Budhiraja R, Gottlieb DJ et al (2012) Rules for scoring respiratory events in sleep: update of the 2007 AASM Manual for the Scoring of Sleep and Associated Events. Deliberations of the Sleep Apnea Definitions Task Force of the American Academy of Sleep Medicine. J Clin Sleep Med 8:597-619

54. Evans AK, Rahbar R, Rogers GF et al (2006) Robin sequence: a retrospective review of 115 patients. Int J Pediatr Otorhinolaryngol 70:973-980

55. Sher AE (1992) Mechanisms of airway obstruction in Robin sequence: implications for treatment. Cleft Palate Craniofac J 29: 224-231

56. Kaban LB, Moses MH, Mulliken JB (1988) Surgical correction of hemifacial microsomia in the growing child. Plast Reconstr Surg 82:9-19

57. Cohen MM Jr (1999) Robin sequences and complexes: causal heterogeneity and pathogenetic/phenotypic variability. Am J Med Genet 84:311-315

58. Breugem CC, Mink van der Molen AB (2009) What is 'Pierre Robin sequence'? J Plast Reconstr Aesthet Surg 62:1555-1558

59. Breugem CC, Courtemanche DJ (2010) Robin sequence: clearing nosologic confusion. Cleft Palate Craniofac J 47:197-200
60. Marques IL, Prado-Oliveira R, Leiriao VH et al (2010) Clinical and fiberoptic endoscopic evaluation of swallowing in robin sequence treated with nasopharyngeal intubation: the importance of feeding facilitating techniques. Cleft Palate Craniofac J 47:523-529

61. Maas C, Poets CF (2014) Initial treatment and early weight gain of children with Robin sequence in Germany: a prospective epidemiological study. Arch Dis Child Fetal Neonatal Ed 99:F491-F494

62. Meyer AC, Lidsky ME, Sampson DE et al (2008) Airway interventions in children with Pierre Robin sequence. Otolaryngol Head Neck Surg 138:782-787

63. Myer CM 3rd, Reed JM, Cotton RT et al (1998) Airway management in Pierre Robin sequence. Otolaryngol Head Neck Surg 118:630-635

64. Kirschner RE, Low DW, Randall P et al (2003) Surgical airway management in Pierre Robin sequence: is there a role for tonguelip adhesion? Cleft Palate Craniofac J 40:13-18

65. Papoff P, Guelfi G, Cicchetti R et al (2013) Outcomes after tonguelip adhesion or mandibular distraction osteogenesis in infants with Pierre Robin sequence and severe airway obstruction. Int J Oral Maxillofac Surg 42:1418-1423

66. Paes EC, Mink van der Molen AB, Muradin MS et al (2013) A systematic review on the outcome of mandibular distraction osteogenesis in infants suffering Robin sequence. Clin Oral Investig 17: $1807-1820$

67. Rogers GF, Murthy AS, LaBrie RA et al (2011) The GILLS score: part I. Patient selection for tongue-lip adhesion in Robin sequence. Plast Reconstr Surg 128:243-251

68. Rogers GF, Lim AA, Mulliken JB et al (2009) Effect of a syndromic diagnosis on mandibular size and sagittal position in Robin sequence. J Oral Maxillofac Surg 67:2323-2331

69. Murage KP, Tholpady SS, Friel M et al (2013) Outcomes analysis of mandibular distraction osteogenesis for the treatment of Pierre Robin sequence. Plast Reconstr Surg 132:419-421

70. Abramowicz S, Bacic JD, Mulliken JB et al (2012) Validation of the GILLS score for tongue-lip adhesion in Robin sequence patients. $\mathrm{J}$ Craniofac Surg 23:382-386

71. Hong P, Brake MK, Cavanagh JP et al (2012) Feeding and mandibular distraction osteogenesis in children with Pierre Robin sequence: a case series of functional outcomes. Int J Pediatr Otorhinolaryngol 76:414-418

72. Hong P, McNeil M, Kearns DB et al (2012) Mandibular distraction osteogenesis in children with Pierre Robin sequence: impact on health-related quality of life. Int J Pediatr Otorhinolaryngol 76: 1159-1163

73. Paes EC, Fouche JJ, Muradin MS et al (2014) Tracheostomy versus mandibular distraction osteogenesis in infants with Robin sequence: a comparative cost analysis. Br J Oral Maxillofac Surg 52:223-229 